\title{
Polymerization of Oriental Lacquer (Urushi) with Epoxidized Linseed Oil as a New Reactive Diluent
}

\author{
Takahisa Ishimura ${ }^{1}$ and Takashi Yoshida ${ }^{1,2}$ \\ ${ }^{1}$ Department of Bio and Environmental Chemistry, Kitami Institute of Technology, 165 Koen-cho, Kitami 090-8507, Japan \\ ${ }^{2}$ Research Center for Environmentally Friendly Materials Engineering, Muroran Institute of Technology, 27-1 Mizumoto-cho, \\ Muroran, Hokkaido 050-8585, Japan \\ Correspondence should be addressed to Takashi Yoshida; yoshida@chem.kitami-it.ac.jp
}

Received 24 February 2015; Accepted 31 May 2015

Academic Editor: Wen Shyang Chow

Copyright (c) 2015 T. Ishimura and T. Yoshida. This is an open access article distributed under the Creative Commons Attribution License, which permits unrestricted use, distribution, and reproduction in any medium, provided the original work is properly cited.

\begin{abstract}
A hybrid lacquer (HBL) paint prepared by combining a natural kurome lacquer (KL) paint and an amino silane reagent, for example, $N$-(2-aminoethyl)-3-aminopropyl triethoxysilane (AATES), produced a polymerized film faster than the KL paint alone. However, the viscosity of the HBL paint was too viscous for easy handling. Addition of $10 \mathrm{wt} \%$ of an epoxidized linseed oil, ELO-6, with $6.4 \mathrm{~mol} \%$ epoxidation as a reactive diluent to the HBL paint decreased the viscosity by $1 / 2$ from $25476 \mathrm{mPa} \cdot \mathrm{s}$ to $12841 \mathrm{mPa} \cdot \mathrm{s}$ and improved the ease of coatability. The polymerization mechanism was elucidated by NMR measurements of extracts from the resulting polymerization films, suggesting that amino groups in the HBL paint reacted with epoxy groups of ELO-6 in the lacquer matrix, and then the complex reacted with double bonds of the urushiol side-chain by autooxidation and cross-linking reactions to give a hard polymerized film with a high quality of color and gloss. These results indicate that the addition of ELO-6 improved the polymerizability of both KL and HBL paints without decreasing the quality of the resulting films.
\end{abstract}

\section{Introduction}

Oriental lacquer (urushi) sap collected from lacquer trees has traditionally been the only natural product that is polymerized by an enzyme, laccase, without any volatile compounds to give a cross-linked polymerized film. Therefore, the lacquer has been used as a natural coating material for containers, tableware, and furniture with high durability and a beautiful glossy surface for more than several thousand years in Japan and other Asian countries [1-3]. Natural lacquer is also expected to be an environment-friendly paint for the next generation.

Lacquer trees are of Asian origin and are known to comprise mainly three species, Rhus verniciflua in East Asia (Japan, China, and Korea), Rhus succedanea in South Asia (Vietnam and Taiwan), and Melanorrhoea usitata in South East Asia (Thailand, Cambodia, and Myanmar) $[1,2]$. The lacquer tree sap is a W/O type emulsion and consists of lipids (urushiol, laccol, and thiol) as the main components, acetoneinsoluble components (polysaccharides, glycoproteins, and enzymes) as emulsifiers and dispersing agents, and water [4].

In the polymerization of lacquer, urushiol, which is a mixture of 3-alkenylcatechols, is radically polymerized by laccase in the first stage, and then the polymer is autooxidized by air in the second stage to give cross-linked polymers [57]. However, the polymerization is affected by temperature and humidity, and the polymerization conditions are limited; that is, $30^{\circ} \mathrm{C}$ temperature and $70 \%$ humidity are necessary over a polymerization time of more than one month. The moisture is necessary for the reoxidation of laccase in the polymerization films with oxygen in the air. Furthermore, the autooxidation in the second-stage polymerization is inhibited by the phenolic hydroxyl groups of the catechol ring. These phenolic hydroxyl groups, which act as an antioxidant, are decreased by the enzymatic oxidation in the first-stage polymerization, and this polymerization obstructs contact 
with unsaturated side-chains [8]. Therefore, a long time is necessary to complete polymerization.

Recently, we developed a hybrid lacquer (HBL) paint to improve the polymerizability of kurome lacquer (KL) paint [9]. When an amine-functionalized organic silane compound (amino silane regent), $\mathrm{N}$-(2-aminoethyl)-3-aminopropyl trimethoxysilane (AATMS), $N$-(2-aminoethyl)-3-aminopropyl triethoxysilane (AATES), or $\mathrm{N}$-(2-aminoethyl)-3-aminopropyl methyl dimethoxysilane (AAMDMS), was added to the KL paint, the polymerization time was shortened to $6 \mathrm{~h}$ in humidity below $55 \%$ and temperature at $20^{\circ} \mathrm{C}[10$, 11]. Therefore, the HBL paint is expected to increase the production of lacquer wear. However, the HBL paint had higher viscosity than the original KL paint due to the increase of polymerized and polycondensed compounds in the firststage polymerization [12]. Viscosity of lacquer paint, in general, decreases the handling properties compared to that of other coating methods of spraying, dipping, and painting by brush.

Plant oil, linseed oil, has been often used as a diluent to decrease the viscosity of lacquer paint and to increase the gloss of the resulting polymerized lacquer film [13, 14]. After polymerization, however, linseed oil sometimes oozes out of the polymerized film. Thus, improvements in polymerizability are required for the general use of lacquer paints and materials in the future. In this paper, we report a new reactive diluent prepared by the epoxidation of linseed oil [15-21]. We found that the epoxidized linseed oil ELO-6 with 6.4 mol\% epoxidation worked effectively in polymerization of both $\mathrm{HBL}$ and natural KL paints without any volatile components. The drying properties and hardness after polymerization of the HBL and KL paints with epoxidized linseed oils as reactive diluents are reported. The polymerization mechanism of $\mathrm{HBL}$ and KL paints with the epoxidized linseed oil was evaluated by NMR measurements of acetone extracts from the corresponding polymerization films.

\section{Materials and Methods}

2.1. Materials. Kurome lacquer (KL) paint was purchased from Dohichu Shoten (Osaka, Japan). The KL paint used here was composed of urushiol (89.6\%), water (4.1\%), and acetone-insoluble compounds $(6.3 \%)$ such as polysaccharides, glycoprotein, and laccase. N-(2-aminoethyl)-3aminopropyl triethoxysilane (AATES) was obtained from Shin-Etsu Silicone Co. Ltd. (Tokyo, Japan). The linseed oil (LO) used was reagent grade.

2.2. Measurements. The drying of lacquer paints was evaluated by using drying time recorder (Taiyu Equipment, Osaka, Japan) according to the JIS-K-5400 standards. The hardness of polymerized films was determined using mechanical pencil hardness tester (Yoshimitsu Seiki, Tokyo, Japan) according to the JIS-K-5600 standards. Viscosity was measured by Brookfield cone-plate type viscometer DV-II+. The $500 \mathrm{MHz}$ ${ }^{1} \mathrm{H}$ NMR spectrum in $\mathrm{CDCl}_{3}$ as a solvent at $25^{\circ} \mathrm{C}$ was obtained by using JEOL JNM-ECA500 spectrometer with tetramethylsilane as a reference $(0.00 \mathrm{ppm})$. Color scales of polymerization films were determined by the color standard
$\left(L^{*} a^{*} b^{*}\right.$ system) using BYK-Gardner Gmbh colorimeter (Germany). Spectroguide $45 / 0$ was used. The symbols, $L^{*}, a^{*}$, and $b^{*}$, mean brightness and the ratios of red $(+)$ to green $(-)$ and yellow $(+)$ to blue $(-)$, respectively. The gloss of the polymerized films was measured by a gloss meter PG-1M (Nippon Denshoku, Japan). Thermogravimetric analysis (TGA) of the polymerized films was performed using Shimadzu DTG60 thermoanalyser at the heating rate of $10^{\circ} \mathrm{C} / \mathrm{min}$ under $\mathrm{N}_{2}$ atmosphere. The glass transition temperature $(\tan \delta$ ) of polymerization films was recorded using a rigid-body pendulum-testing machine RPT-3000W (A\&D Co., Ltd., Japan).

2.3. Synthesis of Epoxidized Linseed Oil [21]. A typical procedure for the epoxidation of linseed oil, ELO-6, with $6.4 \mathrm{~mol} \%$ epoxidation is as follows. To a solution of linseed oil (44.0 g, $50.0 \mathrm{mmol})$ in $\mathrm{CHCl}_{3}(150 \mathrm{~mL})$ were added $0.6 \mathrm{~g}$ of phosphotungstic acid $(0.02 \mathrm{mmol})$ and $0.215 \mathrm{~g}$ of cetylpyridinium chloride $(0.06 \mathrm{mmol})$. After $30 \%$ hydrogen peroxide solution $(5.67 \mathrm{~g}, 50.0 \mathrm{mmol})$ was added, the mixture was refluxed for 6 hours with vigorous stirring. After cooling to room temperature, the separated $\mathrm{CHCl}_{3}$ layer was washed by distilled water twice and then dried over anhydrous sodium sulfate. After filtration and evaporation to remove sodium sulfate and $\mathrm{CHCl}_{3}$, respectively, epoxidized linseed oil (ELO6) (42.0 g) with 6.4 mol\% epoxidation was obtained in $95 \%$ yield. The epoxidized linseed oil was used without further purification.

\subsection{Polymerization of Hybrid Lacquer Paint with ELO-6.} To the KL paint $(10.0 \mathrm{~g})$ was added $1.0 \mathrm{~g}$ of epoxidized linseed oil (ELO-6) as a reactive diluent. The mixture was stirred for $30 \mathrm{~min}$ at room temperature and then $0.5 \mathrm{~g}$ of hydrolyzed AATES that had been prepared by addition of water was added. The mixture was further stirred for $30 \mathrm{~min}$ and then coated at $76 \mu \mathrm{m}$ thickness on a glass plate by using a film applicator. The lacquer-coated glass plate was maintained at $25^{\circ} \mathrm{C}$ under $60 \%$ humidity for the enzymatic and autooxidative polymerization.

2.5. Extraction of Polymerization Films by Acetone. To investigate the polymerizability of epoxidized linseed oil (ELO6 ), the polymerization films of the KL paint with ELO-6 and AATES after polymerization for $2 \mathrm{~h}, 24 \mathrm{~h}$, and $168 \mathrm{~h} \mathrm{(7}$ days), respectively, were extracted by acetone. The extracts were identified by the ${ }^{1} \mathrm{H}$ NMR measurements. The results are shown in Figure 3.

\section{Results and Discussion}

3.1. Synthesis of Epoxidized Linseed Oils. In general, a small amount of oil of linseed (Linum usitatissimum) is used as a diluent of $\mathrm{KL}$ paint to decrease the viscosity and improve the gloss of the surface of the polymerized film. However, linseed oil often oozes out of the polymerization film. Therefore, epoxidized linseed oils as a new reactive diluent were synthesized by the epoxidation of linseed oil with hydrogen peroxide $\left(\mathrm{H}_{2} \mathrm{O}_{2}\right)$ and heteropoly acid-CPC system as a catalyst. Table 1 shows the viscosity of the KL 
TABLE 1: Viscosity of kurome lacquer paint with epoxidized linseed oil.

\begin{tabular}{lcccc}
\hline Number & \multicolumn{2}{c}{$\begin{array}{c}\text { Epoxidized linseed oil } \\
\text { Degree of epoxidation } \\
\%\end{array}$} & $\begin{array}{c}\text { Viscosity } \\
\text { mPa·s }\end{array}$ & $\begin{array}{c}\text { Viscosity of mixture }^{\mathrm{b}} \\
\mathrm{mPa} \cdot \mathrm{s}\end{array}$ \\
\hline 1 & ELO-6 & 6.4 & 51.4 & 2382 \\
2 & ELO-25 & 24.8 & 109.9 & 3866 \\
3 & ELO-43 & 42.6 & 183.1 & 4246 \\
4 & ELO-100 & 100 & 601.7 & 6904 \\
\hline 5 & LO & - & 51.0 & $2983^{\mathrm{c}}$ \\
6 & None & & - & 4598 \\
\hline
\end{tabular}

${ }^{\mathrm{a}}$ The degree of epoxidation was calculated from ${ }^{1} \mathrm{H}$ NMR spectra.

${ }^{b}$ Epoxidized linseed oils (ELO) were mixed in the kurome lacquer (KL) paint in the weight proportion of 1:10 and then viscosity was measured by the DV-II+ viscometer at room temperature.

${ }^{c}$ Phase separation occurred.

TABle 2: Polymerization of lacquer paints with epoxidized linseed oil ELO-6.

\begin{tabular}{|c|c|c|c|c|c|c|c|c|c|c|c|c|c|}
\hline \multirow{3}{*}{ Number } & \multicolumn{3}{|c|}{ Paint $^{\mathrm{a}}$} & \multicolumn{2}{|c|}{ Polymerization time ${ }^{\mathrm{b}}$} & \multicolumn{8}{|c|}{ Polymerization film after 7 days $^{c}$} \\
\hline & \multirow{2}{*}{\multicolumn{2}{|c|}{ ELO-6 }} & \multirow{2}{*}{$\begin{array}{c}\text { Viscosity } \\
\mathrm{mPa} \cdot \mathrm{s}\end{array}$} & \multirow{2}{*}{$\mathrm{TF}$} & \multirow[t]{2}{*}{$\mathrm{HD}$} & \multirow{2}{*}{$\begin{array}{c}\text { Pencil } \\
\text { hardness }\end{array}$} & \multicolumn{3}{|c|}{ Color scale } & \multirow{2}{*}{$\begin{array}{c}\text { Gloss } \\
60^{\circ}\end{array}$} & \multirow{2}{*}{$\begin{array}{l}\mathrm{T}_{g} \\
{ }^{\circ} \mathrm{C}\end{array}$} & \multirow{2}{*}{$\begin{array}{l}\text { Weight loss at } 20 \% \\
{ }^{\circ} \mathrm{C}\end{array}$} & \multirow{2}{*}{$\begin{array}{c}\text { Residue at } 600^{\circ} \mathrm{C} \\
\%\end{array}$} \\
\hline & & & & & & & $L^{*}$ & $a^{*}$ & $b^{*}$ & & & & \\
\hline 1 & KL & - & 4598 & 4.4 & 8.6 & $\mathrm{HB}$ & 3.41 & 13.00 & 4.41 & 88.5 & 90.1 & 406 & 0.8 \\
\hline 2 & $\mathrm{KL}$ & $\bigcirc$ & 2382 & 2.3 & 3.8 & $\mathrm{~F}$ & 1.39 & 5.42 & 1.78 & 84.3 & 95.5 & 377 & 17.7 \\
\hline 3 & $\mathrm{HBL}$ & - & 25476 & 1.2 & 2.0 & F & 0.95 & 0.61 & 0.56 & 76.2 & 101.8 & 419 & 29.6 \\
\hline 4 & HBL & $\bigcirc$ & 12841 & 1.1 & 2.0 & F & 0.59 & 0.38 & 9.47 & 86.9 & 131.8 & 380 & 28.7 \\
\hline
\end{tabular}

${ }^{a}$ The KL (kurome lacquer) and HBL (hybrid lacquer) paints with ELO-6 (6.4 mol\% epoxidation) were prepared in the weight proportions as follows. KL: EOL-6 = $10: 1$ for number 2, KL: hydrolyzed AATES = $10: 1$ for number 3, and KL: hydrolyzed AATES : ELO-6 = 10:1:0.25 for number 4, respectively. Viscosity was measured by the DV-II+ viscometer at room temperature.

${ }^{\mathrm{b}}$ Polymerization time was measured by touch-free (TF) polymerization state and hard (HD) polymerization state under $20-25^{\circ} \mathrm{C}$ at $55-60 \%$ humidity.

${ }^{c}$ Pencil hardness was recorded by the JIS-K 5400 drying recorder. Color scale was measured by the BYK-Gardner according to the spectro-guide $45 / 0$.

$L^{*}$ means brightness, $a^{*}$ means + red/-green, and $b^{*}$ means +yellow/-blue, respectively. The gloss $\left(60^{\circ}\right)$ of polymerized film was obtained by the PG-1M glossmeter.

The glass transition temperature $\left(T_{g}\right)$ measurement was carried out with the RPT-3000W rigid-body pendulum-testing (RPT) machine.

Temperature of weight loss at $20 \mathrm{wt} \%$ and residue at $600^{\circ} \mathrm{C}$ were recorded by the DTG-60 thermoanalyser at the heating rate of $10^{\circ} \mathrm{C}$ under $\mathrm{N}_{2}$ atmosphere.

paint with ELOs in the weight proportion of $10: 1$. The viscosity of the KL paint was $4598 \mathrm{mPa} \cdot \mathrm{s}$ (number 6). Linseed oil decreased its viscosity to $2983 \mathrm{mPa} \cdot \mathrm{s}$ (number 5), but a phase separation occurred at that proportion. When ELO6 with $6.4 \mathrm{~mol} \%$ epoxidation was used, the viscosity of the $\mathrm{KL}$ paint was found to decrease to $2382 \mathrm{mPa} \cdot \mathrm{s}$ (number 1), and no phase separation occurred at that proportion. The viscosity of the KL paint increased gradually as the degree of epoxidation of the added linseed oil increased. ELO-43 (number 1) with $43 \mathrm{~mol} \%$ epoxidation gave almost the same viscosity $(4246 \mathrm{mPa} \cdot \mathrm{s})$ as that of the KL paint $(4598 \mathrm{mPa} \cdot \mathrm{s})$, as shown in number 6 , and phase separation occurred. With proportions of ELOs higher than $10 \mathrm{wt} \%$ being added to the KL paint, a phase separation of the KL paint occurred except with ELO-6. Therefore, ELO-6 was used as a reactive diluent for both KL and HBL paints in this work.

3.2. Polymerization of $K L$ and HBL Paints with ELO-6. Table 2 shows the results of polymerization of the KL and HBL paints with and without ELO-6. The polymerization times of the paints and the color and gloss of the resulting polymerized films were quantitatively compared to those of the polymerized film of the KL paint. The glass transition temperature and thermostability were also compared. The HBL paint that was obtained from the KL paint and hydrolyzed AATES in the weight proportion of $10: 0.5$ had high viscosity of $25476 \mathrm{mPa} \cdot \mathrm{s}$, so that the HBL paint could not be used directly as paint. When $10 \mathrm{wt} \%$ of ELO- 6 was added to both KL and HBL paints in the proportion of $1: 10$ (numbers 2 and 4), the viscosities decreased by half of the original to 2382 and $12841 \mathrm{mPa} \cdot \mathrm{s}$, respectively, suggesting that ELO-6 worked effectively as a diluent.

The paint was coated on a glass plate at $76 \mu \mathrm{m}$ thick by using a film applicator and then the polymerization time and pencil hardness were measured after polymerization. The original KL paint (number 1) was polymerized to touchfree $(\mathrm{TH})$ and hard (HD) polymerization states in 4.4 and $8.6 \mathrm{~h}$, respectively, as measured by the drying time recorder. Addition of ELO-6 to the KL paint accelerated the polymerization time to half in both touch-free (TH) and hard (HD) polymerization states (number 2). For the HBL paint (number 4), the polymerization time was the same whether or not ELO-6 was added, because the polymerization rate of the HBL paint was originally fast, but the viscosity of the HBL 


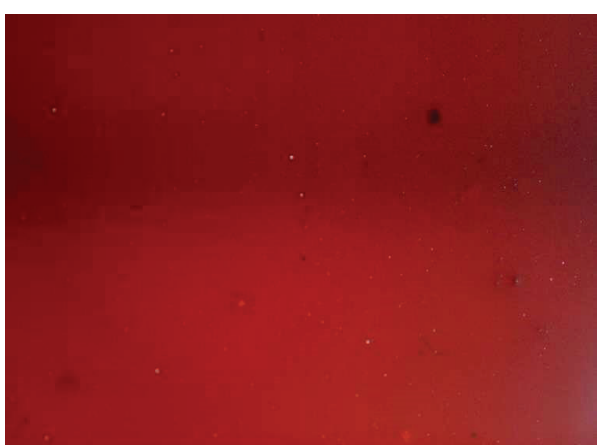

(a)

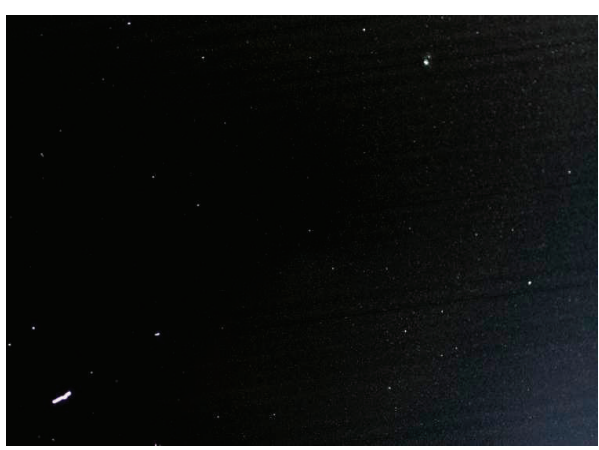

(c)

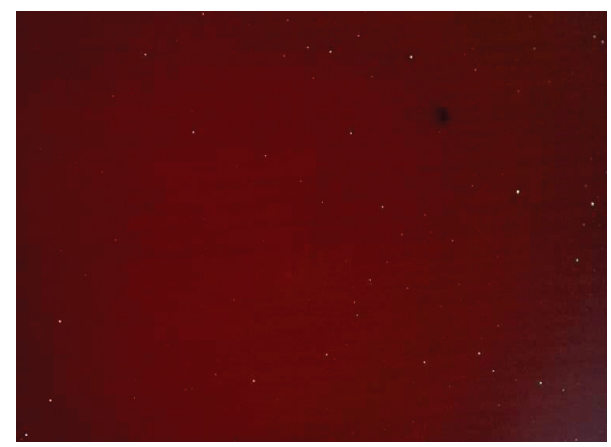

(b)

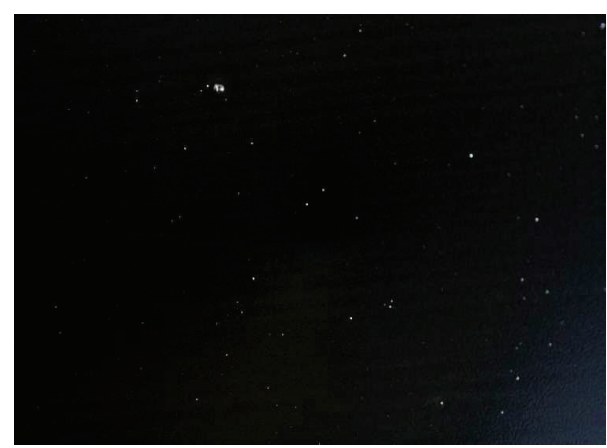

(d)

FIgure 1: Polymerized films of the KL and HBL paints. (a) KL paint, (b) KL paint with ELO-6 at $10: 1$ by weight, (c) HBL paint, and (d) HBL paint with ELO-6 at $10: 1$ by weight.

paint without ELO-6 was too high (number 3). These results indicate that ELO-6 increased the polymerizability of both $\mathrm{KL}$ and HBL paints and decreased the viscosity. After 7 days, the pencil hardness of the polymerized films (numbers 2-4) reached $F$.

The color scale, gloss, and thermal properties of the polymerized films were also measured and are shown in Table 2 . The color scale was evaluated quantitatively by the brightness $\left(L^{*}\right)$, red-green $\left(a^{*}\right)$, and yellow-blue $\left(b^{*}\right)$ proportions, respectively, using the BYK-Gardner apparatus. Larger numbers mean stronger proportions of brightness, red, and yellow, respectively. Figure 1 shows photos of polymerized films of the KL and HBL paints, in which Figure 1(a) is the polymerized film of the KL paint, Figure 1(b) is the KL paint with ELO-6 in the proportion by weight of $10: 1$, Figure 1(c) is the HBL paint, and Figure 1(d) is the HBL paint with ELO6 in the proportion by weight of $10: 1$. For the KL paint (number 1 in Table 1), the values of color scale were relatively large, and the polymerized film seems to be light brown with a little red, as shown in Figure 1(a). For the HBL paint (number 3), the values were smaller, and the polymerization film showed a black color (Figure 1(c)). Addition of ELO6 made the color slightly deeper as shown in Figures 1(b) and $1(\mathrm{~d})$, respectively. The surface of the polymerized films (numbers 2-4) remained glossy because they had almost the same gloss values as the film of the KL paint (number 1).

The glass transition temperature $\left(T_{q}\right)$ of the films was measured by the rigid-body pendulum-testing apparatus,

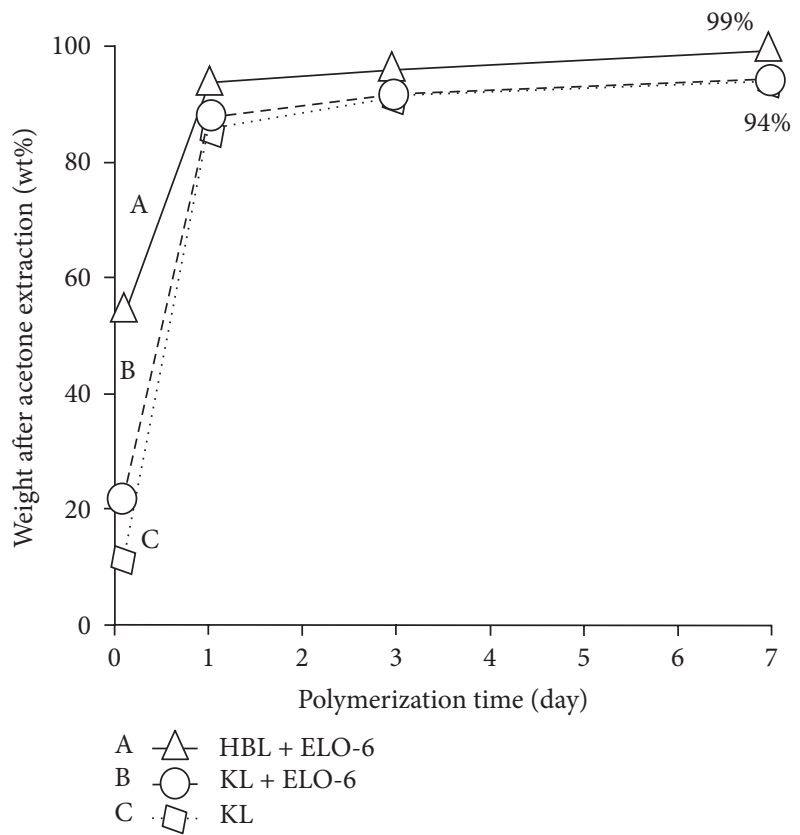

FIGURE 2: Extraction of polymerized film by acetone. After 7 days of polymerization, the weight of the film of the HBL paint with ELO-6 in the weight proportion of $10: 1$ remained at more than $99 \mathrm{wt} \%$ after extraction with acetone, suggesting that the HBL paint with ELO-6 was completely copolymerized. 


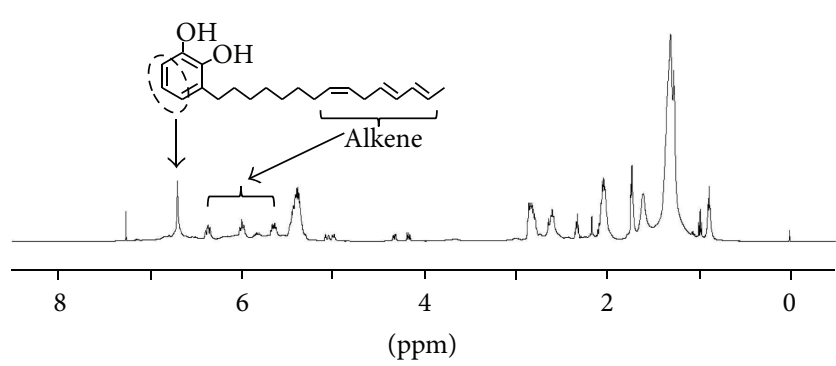

(a)

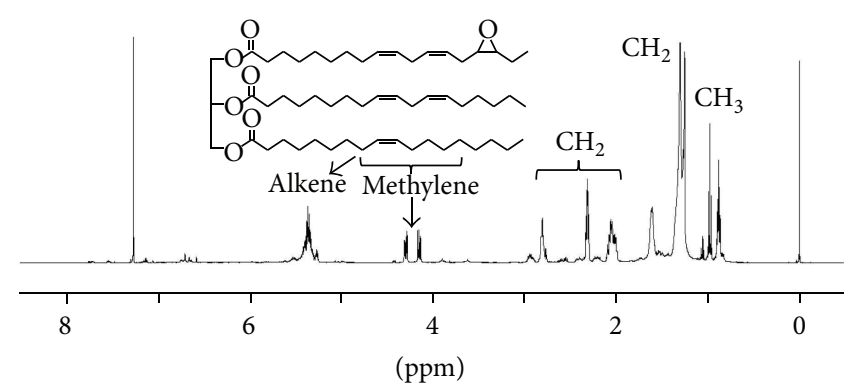

(b)

FIGURE 3: $500 \mathrm{MHz}{ }^{1} \mathrm{H}$ NMR spectra of acetone extracts from polymerization films after (a) $2 \mathrm{~h}$ and (b) $24 \mathrm{~h}$ polymerization, respectively. The polymerization of the KL paint was carried out with ELO- 6 in the weight proportion of $10: 1$. The spectra were obtained in $\mathrm{CDCl}_{3}$ as solvent at $30^{\circ} \mathrm{C}$.

and the temperature of the loss of $20 \%$ weight and residual weights at $600^{\circ} \mathrm{C}$ were analyzed by the DTG thermal analyzer. The film of the HBL paint with ELO-6 (number 4) had the highest $T_{g}$ of $131.8^{\circ} \mathrm{C}$ and $20 \%$ of the weight was lost at $377^{\circ}$ (number 2) and $380^{\circ} \mathrm{C}$ (number 4 ). We found that the HBL films with and without ELO- 6 showed the highest thermal stability and the residues at $600^{\circ} \mathrm{C}$ still remained at $29.6 \%$ and $28.7 \%$ of the feed, respectively. One of the reasons why the thermal stability increased was assumed to be that the complex cross-linking which occurred radically between urushiol, the amino silane coupling reagent, epoxy group, and unsaturated double bonds of side-chains in ELO6 by the autooxidation by air in the second stage of lacquer polymerization. The polymerization films gave no acetone extracts as described below.

3.3. Estimated Polymerization Mechanism. To elucidate the polymerization mechanism of the KL and $\mathrm{HBL}$ paints with ELO-6, acetone extraction of the resulting films was performed $2 \mathrm{~h}$ and $24 \mathrm{~h}$ after coating on the glass plate. Figure 2 shows the weights of polymerization films after acetone extraction. The films of the KL paint with and without ELO6 had weight loss of $6 \%$. No weight loss of the film of the HBL paint with ELO- 6 was observed. The structure of the acetone extracts from the polymerized film of the KL paint with ELO-6 was analyzed by the NMR measurement as shown in Figure 3. After $2 \mathrm{~h}$ polymerization, urushiol was the main extract and small signals due to ELO-6 appeared (Figure 3(a)); however, after $24 \mathrm{~h}$, urushiol was completely polymerized and only ELO- 6 was detected from the film of the KL paint with ELO-6 (Figure 3(b)). Polymerization of urushiol proceeds by two reaction stages; the first stage is the reaction by laccase to obtain urushiol oligomers and then, in the second stage, autooxidation by air occurred to afford cross-linked polymers. Based on the polymerization time of the KL paint with ELO-6, the double bonds of ELO-6-amino silane reagent-urushiol complex 2, as shown in Scheme 1, also reacted with urushiol double bonds in the second-stage polymerization to give cross-linked lacquer polymers composed of urushiol, amino silane reagent, and linseed oil. On the other hand, no extracts were obtained from the HBL paint with ELO- 6 after $2 \mathrm{~h}$ and $24 \mathrm{~h}$ polymerization, indicating that ELO- 6 reacted with the $\mathrm{HBL}$ paint to give a copolymerized film that consisted of HBL and ELO- 6 units.

Scheme 1 illustrates the proposed polymerization mechanism of the HBL paint with ELO-6. Based on the recent results on the polymerization of the $\mathrm{HBL}$ paint [11], the alcoholysis reaction of the amino silane reagent, $\mathrm{N}$-(2aminoethyl)-3-aminopropyl trialkylsilane, with a hydroxyl group of urushiol occurred rapidly to give hybrid product 1 and then the next urushiol continuously reacted with 1 to give hybrid oligomers. At the same time, enzymatic polymerization of urushiol by laccase and the subsequent autooxidation by air formed cross-linked polymerized film in shorter time than the polymerization of the original KL paint. On the other hand, the amino group of hybrid product 1 also reacted with the epoxy group of ELO-6 to produce product 2 by a covalent bond, which was polymerized in the lacquer emulsion containing urushiol oligomers 2 by the autooxidation by air to give the cross-linked polymerized films. Therefore, no acetone extracts were obtained from the HBL film with ELO-6, as shown in Figure 2.

\section{Conclusion}

The epoxidized linseed oil ELO- 6 with 6.4 mol\% epoxidation was found to work effectively as a reactive diluent in the HBL paint matrix. The viscosity and polymerization time of the HBL paint with ELO-6 decreased to half compared to those of the original HBL paint and polymerized films with pencil hardness of $F$ were obtained. The surface was almost as glossy as that of the film polymerized by the original KL paint. The polymerization mechanism was shown by the NMR measurements of the acetone extracts of the polymerized films of the KL and HBL paints with ELO- 6 after $2 \mathrm{~h}$ and $24 \mathrm{~h}$, suggesting that the HBL paint reacted quickly with ELO-6 to give a polymerized film with hard and glossy surface. On the other hand, the reaction of the KL paint with ELO- 6 was slow. These results indicate that the amino group of the HBL paint reacted rapidly with the epoxy group of ELO- 6 and then the autooxidation by air occurred to produce the cross-linked polymerized film. Major difference of current and other papers is that our method gave both short polymerization time of urushiol and glossy polymerized surface of oriental 


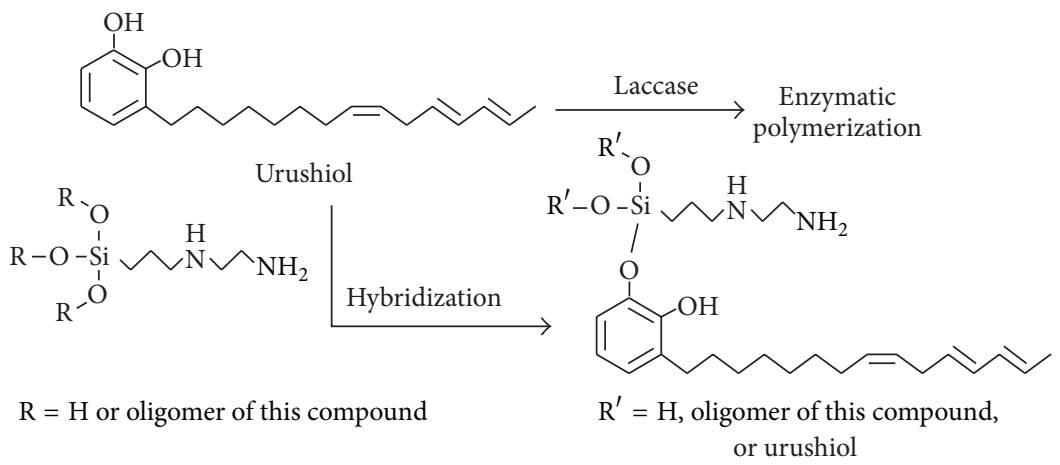

(1)

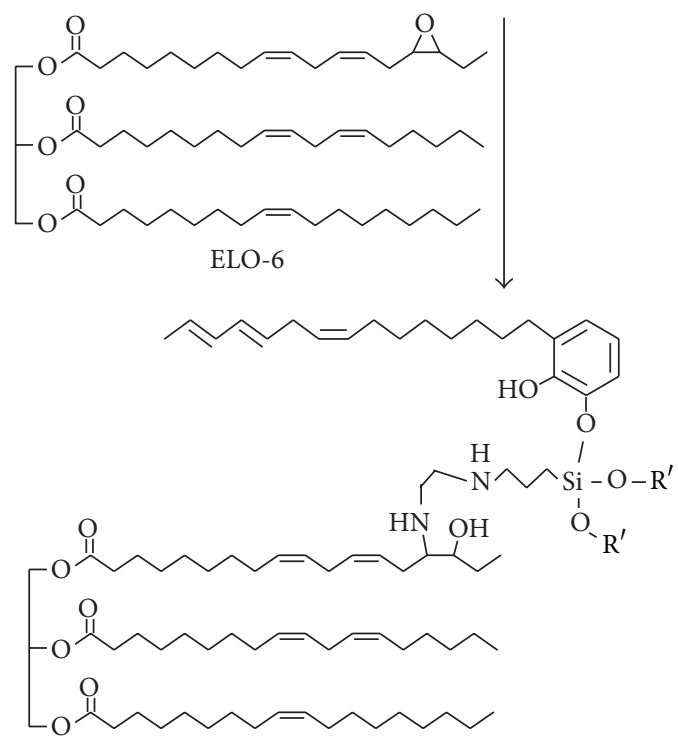

(2)

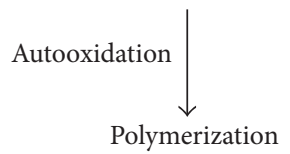

SCHEME 1: Proposed polymerization mechanism of HBL paint with the epoxidized linseed oil ELO-6. The proportions of amino silane reagent and ELO-6 were 2.5 and $10 \mathrm{~mol} \%$ of the KL paint, respectively.

lacquer by addition of alkoxy aminosilane compounds and reactive epoxidized linseed oil. Further studies to elucidate the polymerization mechanism and development of a new lacquer material are now under investigation.

\section{Conflict of Interests}

The authors declare that there is no conflict of interests regarding to the publication of this paper.

\section{Acknowledgments}

The authors are sincerely grateful to Professor T. Miyakoshi and Dr. R. Lu of Meiji University for many discussions and help in this work. This work was partly supported by the Academic Frontier Project for Private Universities, a matching fund subsidy from MEXT (2007-2011), the New Energy and
Industrial Technology Development Organization (NEDO) of Japan, Research Project Grant B by Institute of Science and Technology, Meiji University, and Research Project Grant for Youth, Meiji University.

\section{References}

[1] J. Kumanotani, "Urushi (oriental lacquer) - a natural aesthetic durable and future-promising coating," Progress in Organic Coatings, vol. 26, no. 2-4, pp. 163-195, 1995.

[2] J. Kumanotani, "Enzyme catalyzed durable and authentic oriental lacquer: a natural microgel-printable coating by polysaccharide-glycoprotein-phenolic lipid complexes," Progress in Organic Coatings, vol. 34, no. 1-4, pp. 135-146, 1997.

[3] O. Vogl, "Oriental lacquer, poison ivy, and drying oils," Journal of Polymer Science Part A: Polymer Chemistry, vol. 38, no. 24, pp. 4327-4335, 2000. 
[4] B. Reinhammar, "Purification and properties of laccase and stellacyanin from Rhus vernicifera," Biochimistry and Biophysics Acta, vol. 205, no. 1, pp. 35-47, 1970.

[5] R. Oshima, Y. Yamauchi, C. Watanabe, and J. Kumanotani, "Enzymic oxidative coupling of urushiol in sap of the lac tree, Rhus vernicifera," Journal of Organic Chemistry, vol. 50, no. 15, pp. 2613-2621, 1985.

[6] H. W.-S. Chan, D. T. Coxon, K. E. Peers, and K. R. Price, "Oxidative reactions of unsaturated lipids," Food Chemistry, vol. 9, no. 1-2, pp. 21-34, 1982.

[7] N. A. Porter, S. E. Caldwell, and K. A. Mills, "Mechanisms of free radical oxidation of unsaturated lipids," Lipids, vol. 30, no. 4, pp. 277-290, 1995.

[8] R. Lu, S. Harigaya, T. Ishimura, K. Nagase, and T. Miyakoshi, "Development of a fast drying lacquer based on raw lacquer sap," Progress in Organic Coatings, vol. 51, no. 3, pp. 238-243, 2004.

[9] R. Lu, T. Ishimura, K. Tsutida, T. Honda, and T. Miyakoshi, "Development of a fast drying hybrid lacquer in a low-relativehumidity environment based on kurome lacquer sap," Journal of Applied Polymer Science, vol. 98, no. 3, pp. 1055-1061, 2005.

[10] I. Takahisa, L. Rong, and M. Tetsuo, "Studies on the reaction mechanism between urushiol and organic silane," Progress in Organic Coatings, vol. 55, no. 1, pp. 66-69, 2006.

[11] T. Ishimura, R. Lu, K. Yamasaki, and T. Miyakoshi, "Effects of hybridization of lacquer sap with organic silane on drying properties," Progress in Organic Coatings, vol. 62, no. 2, pp. 193$198,2008$.

[12] T. Ishimura, R. Lu, K. Yamasaki, and T. Miyakoshi, "Development of an eco-friendly hybrid lacquer based on kurome lacquer sap," Progress in Organic Coatings, vol. 69, no. 1, pp. 12$15,2010$.

[13] V. Pitthard, S. Wei, S. Miklin-Kniefacz, S. Stanek, M. Griesser, and M. Schreiner, "Scientific investigations of antique lacquers from a 17th-century Japanese ornamental cabinet," Archaeometry, vol. 52, no. 6, pp. 1044-1056, 2010.

[14] S. Wei, V. Pintus, V. Pitthard, M. Schreiner, and G. Song, "Analytical characterization of lacquer objects excavated from a Chu tomb in China," Journal of Archaeological Science, vol. 38, no. 10, pp. 2667-2674, 2011.

[15] J. T. P. Derksen, F. P. Cuperus, and P. Kolster, "Paints and coatings from renewable resources," Industrial Crops and Products, vol. 3, no. 4, pp. 225-236, 1995.

[16] J. T. P. Derksen, F. P. Cuperus, and P. Kolster, "Renewable resources in coatings technology: a review," Progress in Organic Coatings, vol. 27, no. 1-4, pp. 45-53, 1996.

[17] W. J. Muizebelt, J. C. Hubert, M. W. F. Nielen, R. P. Klaasen, and K. H. Zabel, "Crosslink mechanisms of high-solids alkyd resins in the presence of reactive diluents," Progress in Organic Coatings, vol. 40, no. 1-4, pp. 121-130, 2000.

[18] J. Samuelsson, P.-E. Sundell, and M. Johansson, "Synthesis and polymerization of a radiation curable hyperbranched resin based on epoxy functional fatty acids," Progress in Organic Coatings, vol. 50, no. 3, pp. 193-198, 2004.

[19] K. Johansson and M. Johansson, "Fatty acid methyl ester as reactive diluent in thermally cured solvent-borne coil-coatingsthe effect of fatty acid pattern on the curing performance and final properties," Progress in Organic Coatings, vol. 63, no. 2, pp. 155-159, 2008.

[20] M. A. R. Meier, J. O. Metzger, and U. S. Schubert, "Plant oil renewable resources as green alternatives in polymer science," Chemical Society Reviews, vol. 36, no. 11, pp. 1788-1802, 2007.
[21] Y. Ishii, K. Yamawaki, T. Ura, H. Yamada, T. Yoshida, and M. Ogawa, "Hydrogen peroxide oxidation catalyzed by heteropoly acids combined with cetylpyridinium chloride: epoxidation of olefins and allylic alcohols, ketonization of alcohols and diols, and oxidative cleavage of 1,2-diols and olefins," Journal of Organic Chemistry, vol. 53, no. 15, pp. 3587-3593, 1988. 

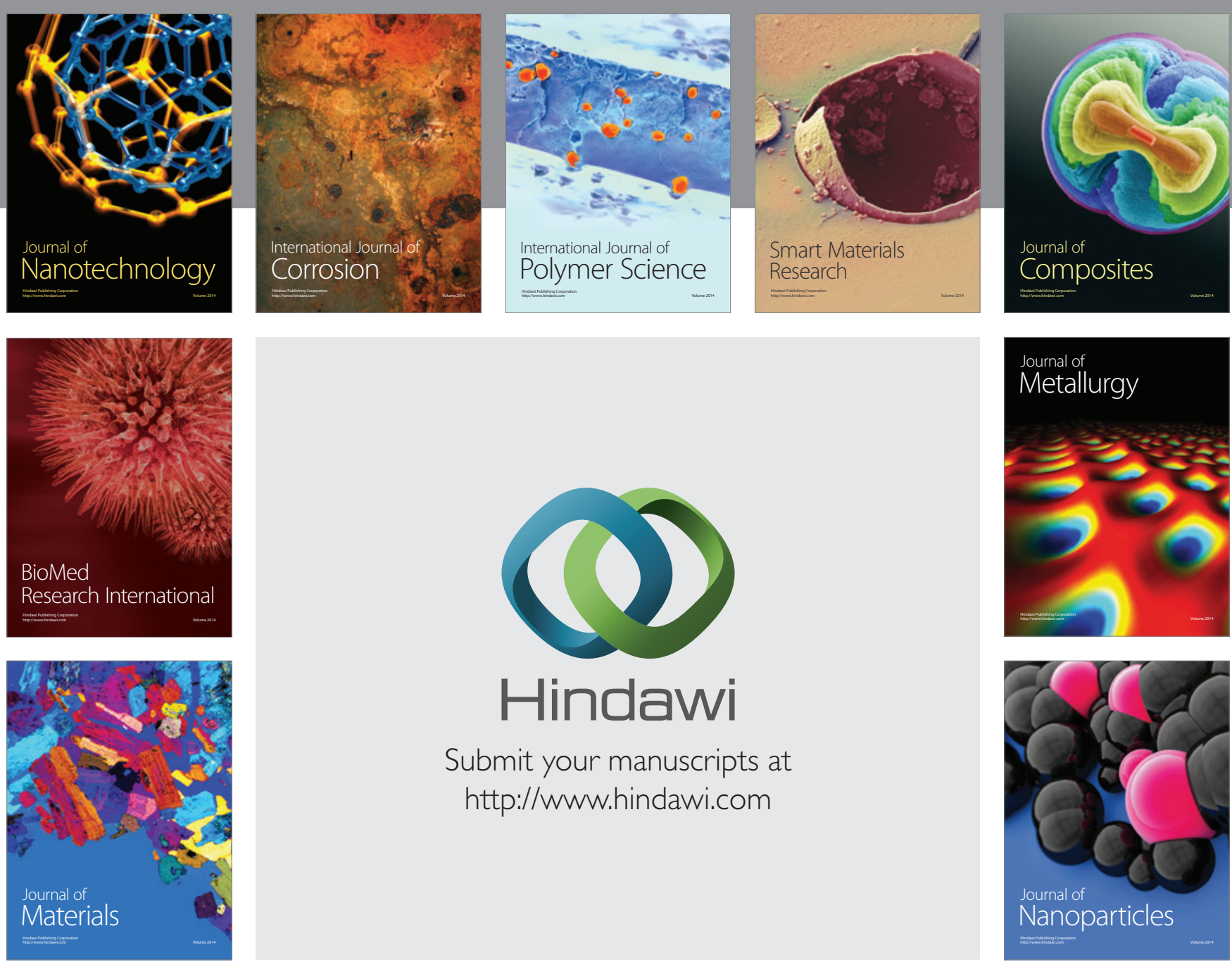

Submit your manuscripts at http://www.hindawi.com
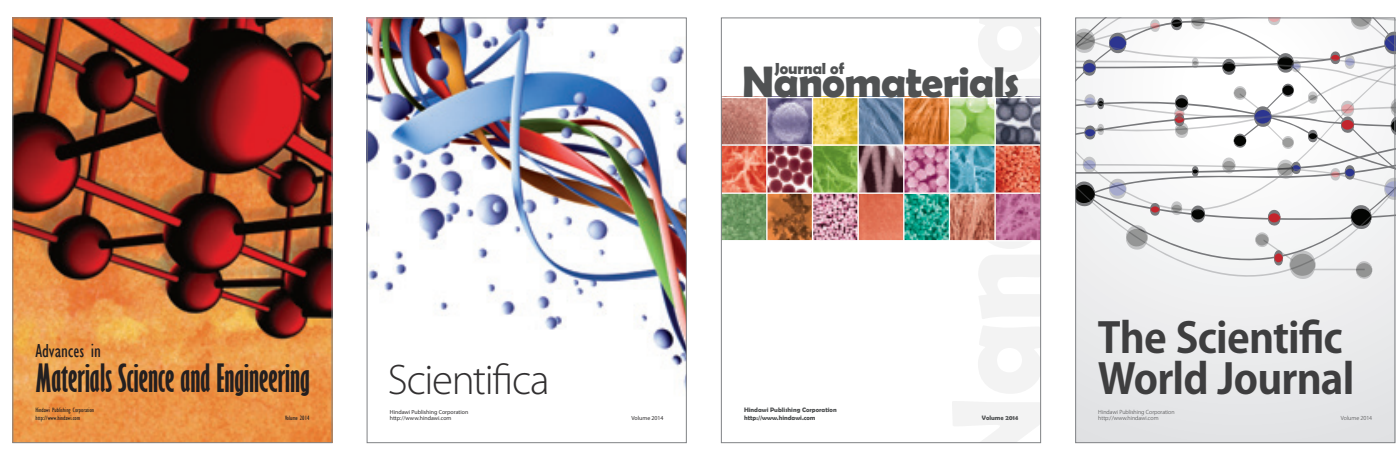

\section{The Scientific World Journal}
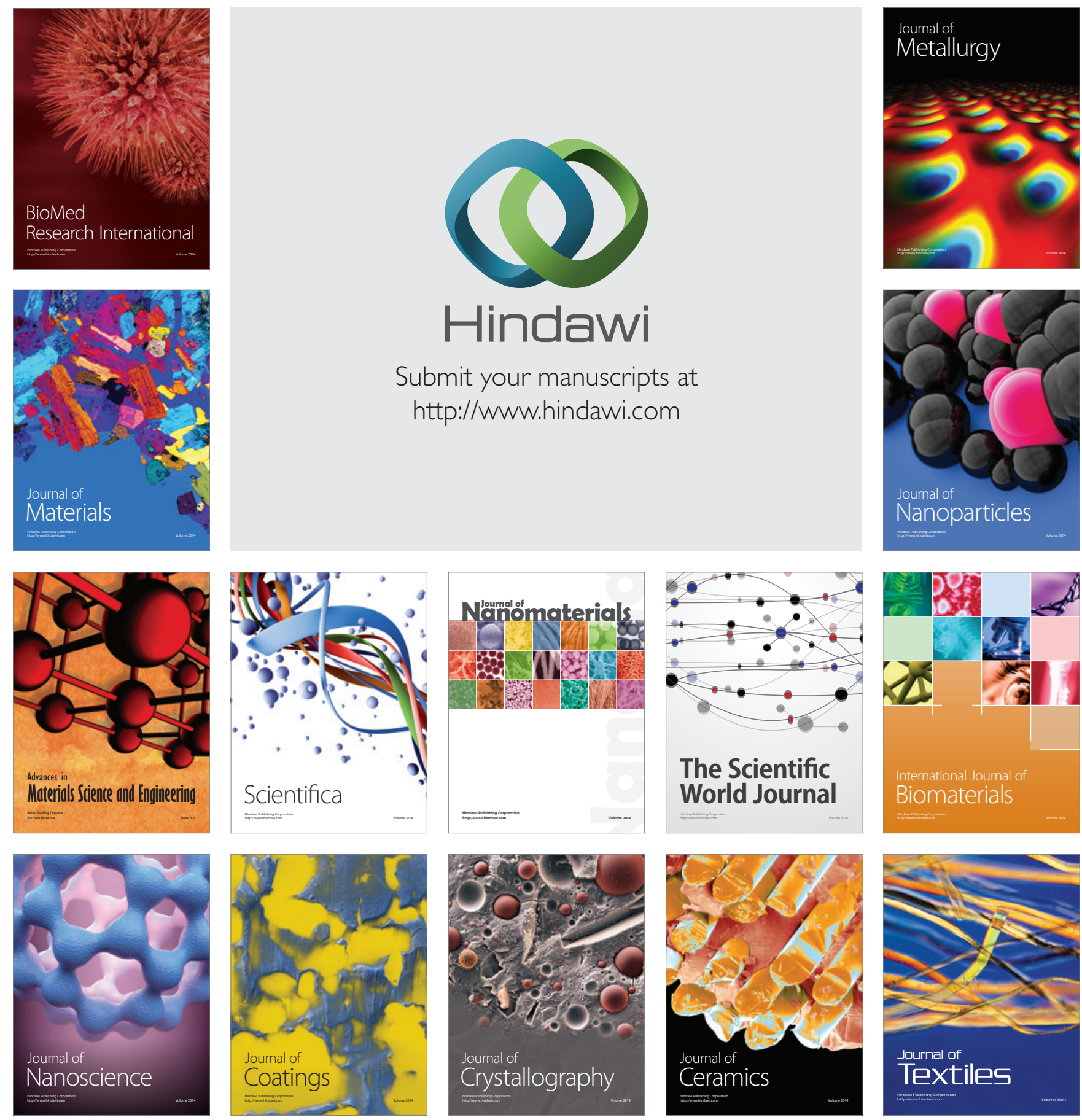